\title{
Comparison of the analgesic effect of ultrasound-guided paravertebral block and ultrasound-guided retrolaminar block in Uniportal video-assisted Thoracoscopic surgery: a prospective, randomized study
}

\author{
Qiang Wang ${ }^{1}$, Shijing Wei ${ }^{1}$, Shuai $\mathrm{Li}^{1}$, Jie $\mathrm{Yu}^{1}$, Guohua Zhang ${ }^{1}$, Cheng $\mathrm{Ni}^{1}$, Li Sun ${ }^{2 *}$ and Hui Zheng ${ }^{1 *}$
}

\begin{abstract}
Background: The optimal modality for postoperative analgesia after uniportal video-assisted thoracoscopic surgery (UVATS) for the treatment of lung cancer has not yet been determined. Both ultrasound-guided paravertebral block (PVB) and retrolaminar block (RLB) have been reported to be successful in providing analgesia after UVATS. However, which block technique provides superior analgesia after UVATS is still unclear. This randomized study was designed to compare the postoperative analgesic effects and adverse events associated with ultrasound-guided PVB and RLB after UVATS.
\end{abstract}

Methods: Sixty patients with lung cancer were randomized to undergo ultrasound-guided PVB (group P) or ultrasoundguided RLB (group R). In group P, $30 \mathrm{~mL}$ of $0.5 \%$ ropivacaine was injected at the T3 and T5 levels via ultrasound-guided PVB ( $15 \mathrm{~mL}$ at each level on the operative side). In group R, $30 \mathrm{~mL}$ of $0.5 \%$ ropivacaine was injected at the $\mathrm{T} 3$ and $\mathrm{T} 5$ levels via ultrasound-guided RLB (15 mL at each level on the operative side). The primary outcome was the numerical rating scale (NRS) score within $48 \mathrm{~h}$ after surgery. The secondary outcomes were total postoperative sufentanil consumption, time to first analgesic request and adverse events.

Results: At 3, 6, 12, 24, 36 and $48 \mathrm{~h}$ postoperatively, the NRS score at rest in group P was lower than that in group $R(p<$ 0.05). At $3,6,12,24$ and $36 \mathrm{~h}$ postoperatively, the NRS score while coughing in group $P$ was lower than that in group $R$ $(p<0.05)$. The total postoperative sufentanil consumption in group $P$ was significantly lower than that in group $R(p<0.001)$. Additionally, the time to first analgesic request was longer in group $R$ than in group $P(p<0.0001)$. The incidence of nausea in group $\mathrm{R}$ was higher than that in group $\mathrm{P}(p<0.05)$.

\footnotetext{
*Correspondence: sunli_zlyy@163.com; zhenghui_zlyy@163.com

${ }^{2}$ Department of Anesthesiology, National Cancer Center/National Clinical Research Center for Cancer/Cancer Hospital \& Shenzhen Hospital, Chinese Academy of Medical Sciences and Peking Union Medical College, Shenzhen 518116, China

'Department of Anesthesiology, National Cancer Center/National Clinical Research Center for Cancer/Cancer Hospital, Chinese Academy of Medical Sciences and Peking Union Medical College, No. 17, Panjiayuannanli,

Chaoyang District, Beijing 100021, China
}

(c) The Author(s). 2021 Open Access This article is licensed under a Creative Commons Attribution 4.0 International License, which permits use, sharing, adaptation, distribution and reproduction in any medium or format, as long as you give appropriate credit to the original author(s) and the source, provide a link to the Creative Commons licence, and indicate if changes were made. The images or other third party material in this article are included in the article's Creative Commons licence, unless indicated otherwise in a credit line to the material. If material is not included in the article's Creative Commons licence and your intended use is not permitted by statutory regulation or exceeds the permitted use, you will need to obtain permission directly from the copyright holder. To view a copy of this licence, visit http://creativecommons.org/licenses/by/4.0/. The Creative Commons Public Domain Dedication waiver (http://creativecommons.org/publicdomain/zero/1.0/) applies to the data made available in this article, unless otherwise stated in a credit line to the data. 
Conclusions: In patients with lung cancer undergoing UVATS, ultrasound-guided PVB with $0.5 \%$ ropivacaine provides better analgesia and results in less nausea than ultrasound-guided RLB. Compared with ultrasound-guided RLB, ultrasound-guided PVB seems to be a better technique for analgesia in UVATS.

Trial registration: The name of this study is the Effect And Mechanism Of Ultrasound-guided Multimodal Regional Nerve Block On Acute And Chronic Pain After Thoracic Surgery. This study was registered in the Chinese Clinical Trial Registry (ChiCTR2100044060). The date of registration was March 9, 2021.

Keywords: Lung cancer, Uniportal video-assisted thoracoscopic surgery, Pain, Ultrasound-guided paravertebral block, Ultrasound-guided retrolaminar block, Adverse events

\section{Background}

Lung cancer is by far the leading cause of cancer-related death in both men and women worldwide [1]. Surgical resection remains the main treatment for operable lung cancer patients [2]. However, lung cancer surgery can lead to severe postoperative pain [3]. With the popularization of video-assisted thoracoscopic minimally invasive surgery, the degree of postoperative pain has decreased compared with the degree of postoperative pain after open surgery, which is mainly due to the use of completely non-ribspreading techniques [4]. Furthermore, with the widespread use of uniportal video-assisted thoracoscopic surgery (UVATS) techniques, postoperative pain is further relieved, which is mainly due to the minimal invasiveness of UVATS [5]. However, the postoperative pain of UVATS remains intense due to injury to the intercostal nerve, incisions in muscle and fascial tissue, and postoperative respiratory pain caused by thoracic drainage tube placement [5].

At present, the optimal modality for postoperative analgesia after UVATS has not yet been determined. Therefore, strategies to alleviate postoperative pain after UVATS with different analgesic techniques have been increasingly investigated [6]. Several ultrasoundguided thoracic nerve block techniques have been explored for perioperative analgesia in minimally invasive VATS, such as ultrasound-guided paravertebral block (PVB) and ultrasound-guided retrolaminar block (RLB) $[6,7]$. PVB is a classic nerve block technique that has been shown to be effective in alleviating postoperative pain and opioid consumption after minimally invasive VATS [8]. However, there is a risk of unintentional iatrogenic pneumothorax and hydropneumothorax because the parietal pleura forms the anterior wall of the paravertebral space [9-11]. In addition, because the foramina form part of the medial wall of the paravertebral space, the risk of accidentally injuring the spinal nerve roots still exists [12]. Furthermore, with dual-plane or triple-plane block techniques, which are widely used in clinical practice, the risk of the aforementioned serious complications further increases [13]. Therefore, for novices, ultrasound-guided PVB is an advanced regional nerve block technique that requires a relatively long learning curve [12]. As a consequence, interest in finding effective, simpler and safer thoracic fascia block techniques continues. In recent years, ultrasoundguided RLB has been found to be effective in alleviating postoperative pain after thoracic surgery $[14,15]$. Comparatively, due to the remoteness of the injection site from the pleura and spinal nerve roots and the superficial anatomical location, RLB is a relatively safe and easy nerve block technique for novice practitioners [14]. However, at present, it is not clear which of the two techniques has a better analgesic effect and is more suitable for postoperative analgesia in UVATS. Therefore, this prospective, randomized clinical study was performed to investigate which technique is better for postoperative analgesia in UVATS.

\section{Methods}

\section{Trial design and inclusion and exclusion criteria}

This prospective, randomized clinical study was approved by the institutional ethics committee of the National Cancer Center/National Clinical Research Center for Cancer/ Cancer Hospital, Chinese Academy of Medical Sciences and Peking Union Medical College (2020080419244502), and registered in the Chinese Clinical Trial Registry (ChiCTR2100044060). Written informed consent was obtained from all patients. A total of 115 patients with lung cancer with an American Society of Anesthesiologists (ASA) physical status of I or II, aged 18 to 64 years old, who were selected for UVATS between March 2021 and July 2021 were recruited into this study (Fig. 1). All patients were able to communicate well and understood how to evaluate their pain score at rest or during coughing. The major exclusion criteria were as follows: infection at the site of injection for ultrasound-guided PVB or RLB; peripheral neuropathy; coagulation disorder; morbid obesity (body mass index (BMI) more than $40 \mathrm{~kg} / \mathrm{m}^{2}$ ); allergy to ropivacaine; greater than first-degree heart block; hypertension; bradycardia (heart rate (HR) less than 60 beats per min); pregnancy; clinically significant cardiovascular, pulmonary, hepatic or renal disease; psychiatric 


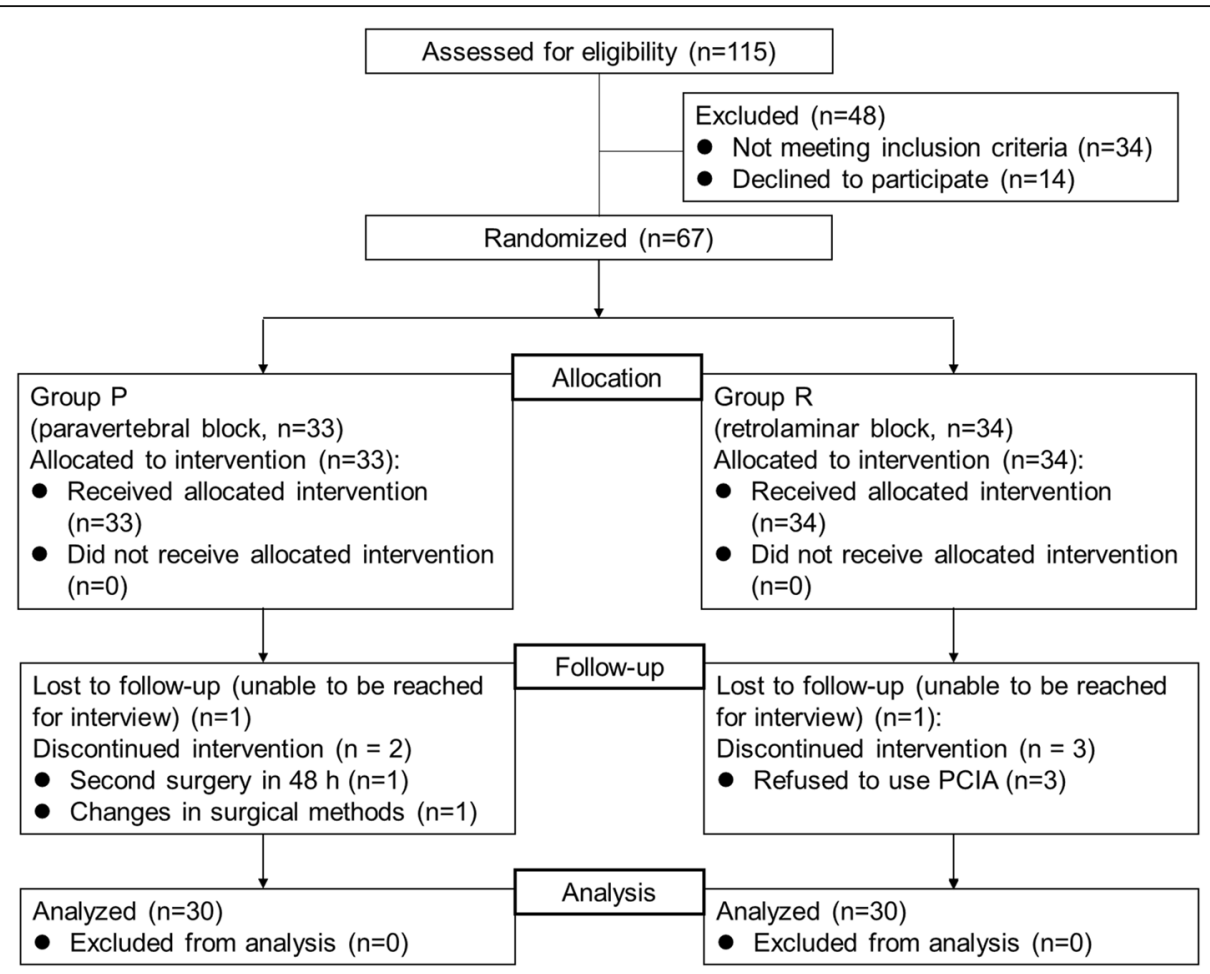

Fig. 1 Patient inclusion and exclusion process. PCIA, patient-controlled intravenous analgesia

illness that would interfere with the pain score assessment; and analgesic drug use within 1 week before surgery. During the preoperative interview, patients were taught how to evaluate their pain score using the numerical rating scale (NRS).

\section{Randomization and block procedures}

Before the study, every patient was trained on how to use the patient-controlled intravenous analgesia (PCIA) pump and instructed on using the NRS, with a score of 0 indicating no pain and a score of 10 indicating the worst imaginable pain. Upon arrival in the nerve block room, the patient was placed in a lateral decubitus position with the operative side up, and standard ASA monitoring, including five-lead electrocardiography and monitoring of the $\mathrm{HR}$, respiratory rate (RR) and pulse oxygen saturation $\left(\mathrm{SpO}_{2}\right)$, was applied. All patients received oxygen through a mask. Sedation and analgesia were provided by intravenous administration of midazolam (1 to $2 \mathrm{mg}$ ) and sufentanil (5 to $10 \mu \mathrm{g}$ ), which were titrated to patient comfort during the whole nerve block procedure. For all patients, a high-frequency linear ultrasound transducer (4-13 MHz, Esaote MyLab 25 Gold, Genoa, Italy) was used to identify the order of the laminae of thoracic vertebrae and paravertebral spaces. After confirmation of satisfactory ultrasound visualization of both potential block sites, patients were randomized using a computer-generated list and opaque, sealed envelopes to one of two treatment groups: (1) ultrasound-guided PVB (group P) or (2) ultrasoundguided RLB (group R). Patients were blinded to the treatment group allocation (Fig. 2).

Under ultrasound guidance, after a skin wheal was raised using $2 \mathrm{ml}$ of $1 \%$ lidocaine, an $80-\mathrm{mm}, 22$-gauge block needle (Stimuplex ${ }^{\circ}$ D Plus; B Braun, Melsungen, Germany) was inserted in-plane in a caudad-to-cephalad direction. In addition, $0.5 \%$ ropivacaine was injected at

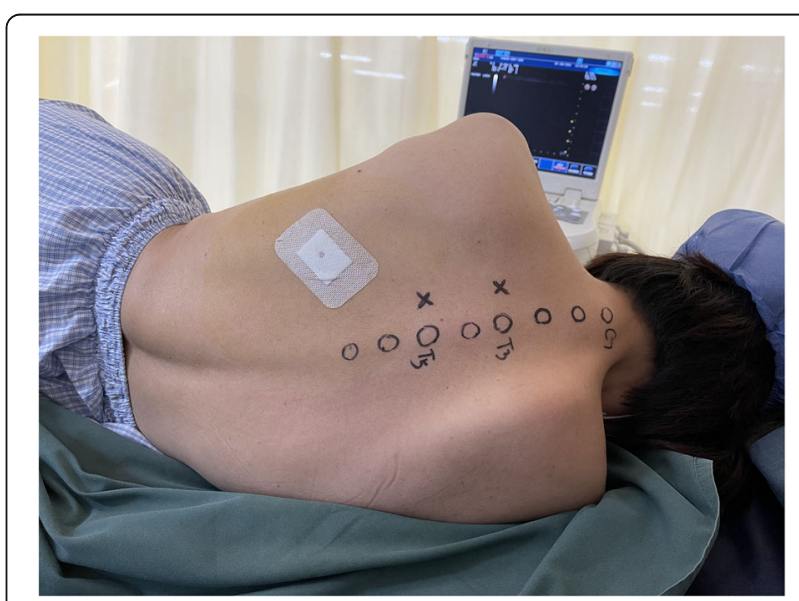

Fig. 2 The T3 and T5 spinal segments where ultrasound-guided PVB or RLB was to be performed 
the appropriate level(s) after negative aspiration $(15 \mathrm{~mL}$ for each level on the operative side) (Fig. 3). For both PVB and RLB, a two-level injection technique was performed at T3 and T5. The nerve block was considered successful if, within $30 \mathrm{~min}$, the patient experienced decreased sensation to pinprick at least from the ipsilateral third to sixth thoracic dermatomes at the level of the anterior axillary line.

\section{Intraoperative and postoperative management}

General anesthesia was induced with $0.05 \mathrm{mg} / \mathrm{kg}$ midazolam, $1.5-2.5 \mathrm{mg} / \mathrm{kg}$ propofol, $0.2-0.4 \mu \mathrm{g} / \mathrm{kg}$ sufentanil and $0.6 \mathrm{mg} / \mathrm{kg}$ rocuronium. General anesthesia was maintained with desflurane, sufentanil and rocuronium. Intraoperative sufentanil was administered at the discretion of the blinded anesthesia team based on cardiovascular responsiveness to noxious stimuli in order to maintain systolic blood pressure within $\pm 20 \%$ of baseline. When the patient's systolic blood pressure increased by more than $20 \%$ from the baseline value, $0.1 \mu \mathrm{g} / \mathrm{kg}$ sufentanil was administered intravenously. After $10 \mathrm{~min}$, if the systolic blood pressure was still higher than $120 \%$ of the baseline value, $0.1 \mu \mathrm{g} / \mathrm{kg}$ sufentanil was again administered intravenously. Ten minutes later, if the systolic blood pressure was still higher than $120 \%$ of baseline after two consecutive sufentanil boluses, $0.5 \mathrm{mg}$ of nicardipine was administered until the systolic blood pressure decreased to baseline $\pm 20 \%$.
During the operation, the velocity of fluid infusion was maintained at $6 \mathrm{~mL} /(\mathrm{kg} . \mathrm{h})$.

After disinfecting the skin in the surgical area, a 5-cmlong incision in the fourth or fifth intercostal space at the anterior axillary line was made (Fig. 4). At the conclusion of the surgical procedure, a chest drain was placed at the edge of the incision (Fig. 4). At the end of the surgery, an intravenous analgesic pump was applied. The PCIA protocol was programmed with $2.5 \mu \mathrm{g} / \mathrm{kg}$ sufentanil diluted to $100 \mathrm{~mL}$ (bolus, $1.5 \mathrm{~mL}$; lockout time interval, $10 \mathrm{~min}$; $1 \mathrm{~h}$ limit, $9 \mathrm{~mL}$ without any baseline infusion). PCIA was administered when the NRS score was $\geq 4$ or at the request of the patient. After surgery, patients were extubated, taken to the postanesthesia care unit (PACU) and received by a nurse anesthetist blinded to the randomization. In addition, a standard PACU care procedure was followed.

\section{Outcomes}

The primary outcome was the NRS score within the 48$h$ period after surgery. The intraoperative sufentanil consumption and total postoperative sufentanil consumption within the 48-h period were also recorded, along with the time at which the patient first required analgesics after nerve block. Before the nerve block procedure (baseline) and at $3 \mathrm{~h}, 6 \mathrm{~h}, 12 \mathrm{~h}, 24 \mathrm{~h}, 36 \mathrm{~h}$ and $48 \mathrm{~h}$ after surgery, the patient's mean arterial pressure (MAP), HR, and NRS scores at rest and during coughing were all

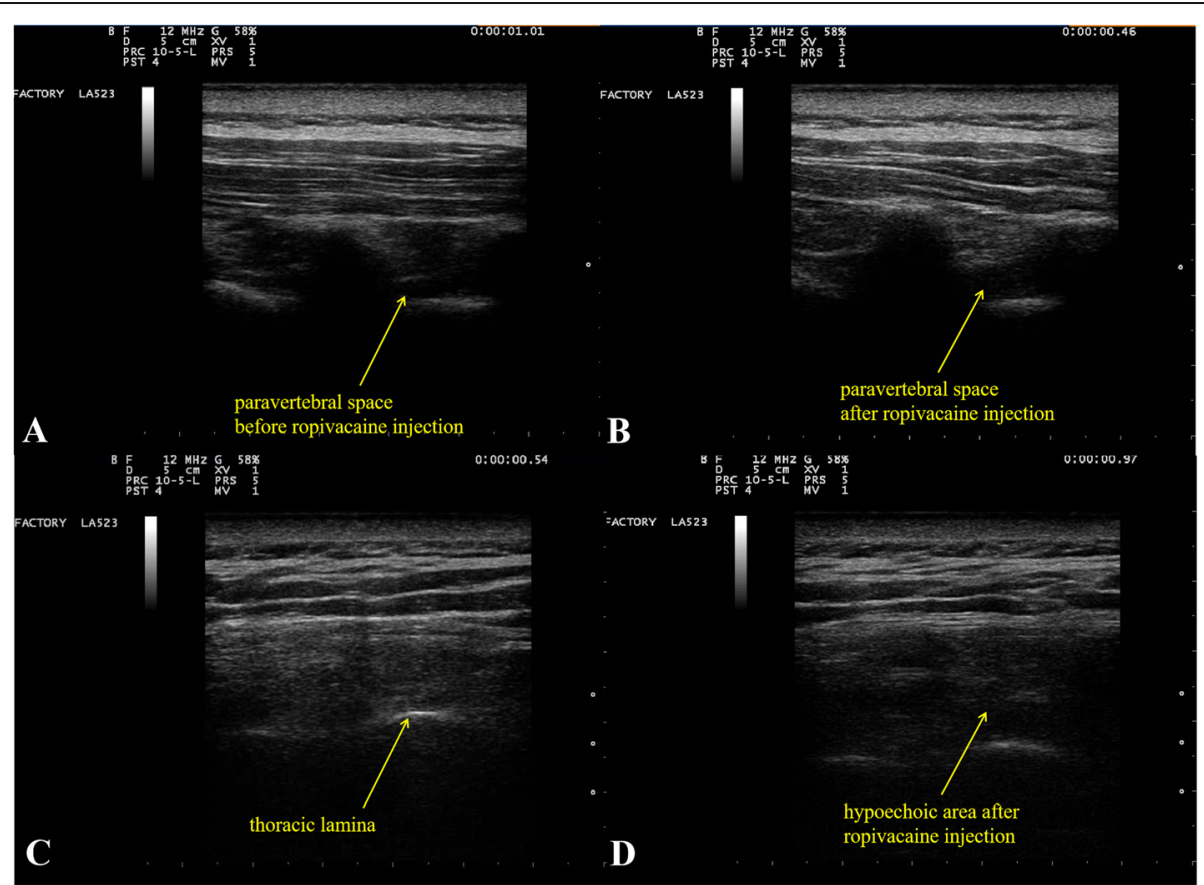

Fig. 3 Ultrasound images of PVB and RLB. A shows an ultrasound image of the paravertebral space before the injection of ropivacaine. B shows that the paravertebral space widened after the injection of $15 \mathrm{ml}$ of ropivacaine. $\mathrm{C}$ shows an ultrasound image of the thoracic lamina before the injection of ropivacaine. D shows the hypoechoic area formed by the injection of ropivacaine above the lamina 


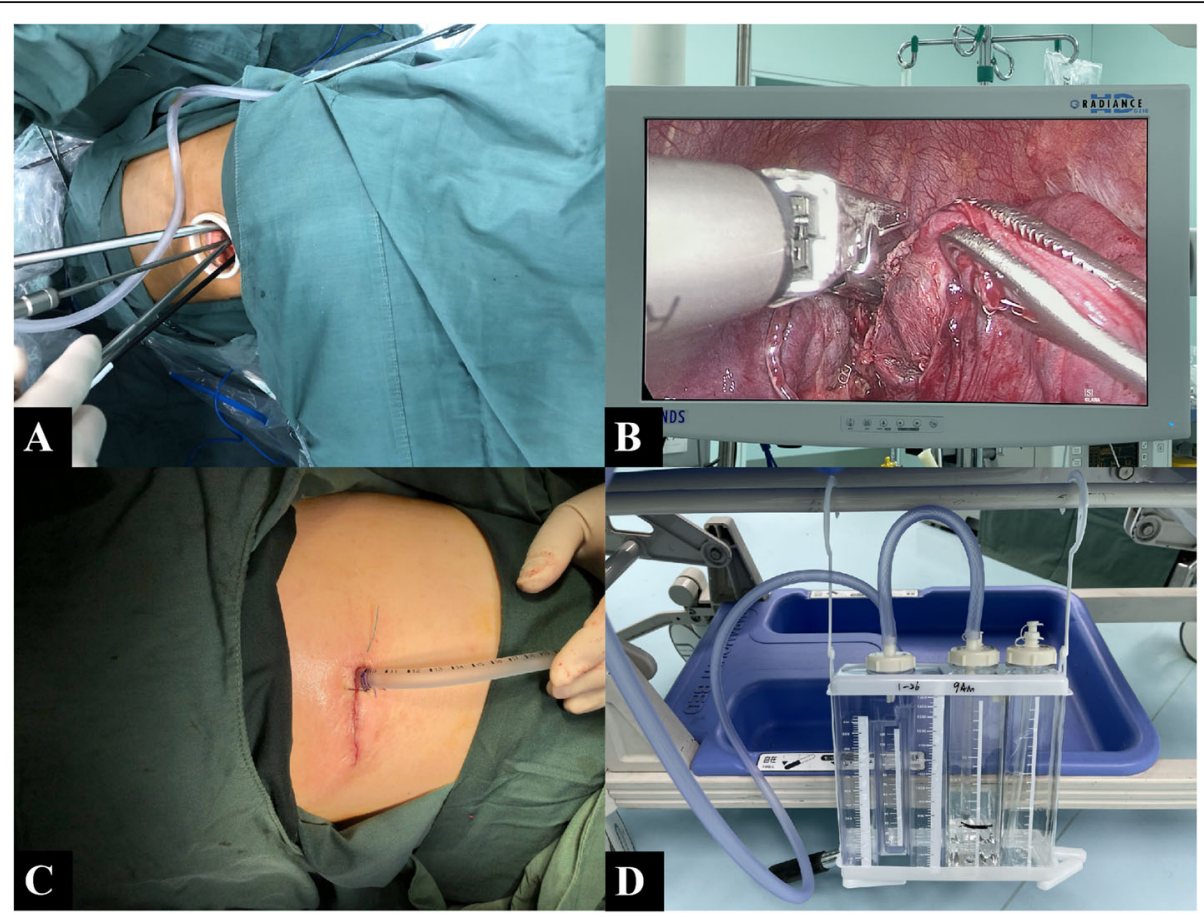

Fig. 4 The 5-cm-long surgical incision was made in the fourth intercostal space at the anterior axillary line (A). B shows the surgical field of thoracoscopic lobectomy. A chest drain was placed at the edge of the incision at the end of the surgery (C). D shows the chest drainage system

assessed. Adverse events, such as bradycardia (HR less than 60 beats per min), hypotension (systolic blood pressure less than $90 \mathrm{mmHg}$ or more than $20 \%$ lower than baseline), hypoxemia $\left(\mathrm{SpO}_{2}\right.$ less than $\left.90 \%\right)$, respiratory depression (RR less than 10 breaths per min lasting for more than $10 \mathrm{~min}$ ), pruritus, neurotoxicity, backache, nausea and vomiting, were recorded after surgery. Bradycardia was treated with intravenous boluses of 0.5 $\mathrm{mg}$ of atropine. Hypotension was treated with $6 \mathrm{mg}$ of ephedrine and $6 \mathrm{ml} / \mathrm{kg}$ normal saline; the same doses were repeated as required. Hypoxemia was treated with inhalation of oxygen through a face mask. Respiratory depression was treated with naloxone and oxygen until the respiratory rate was greater than 15 breaths per min.

In addition, adverse events related to block procedures were recorded. Pneumothorax and/or hydropneumothorax were indicated when patients presented with dyspnea. Physical exam revealed notably decreased breathing sounds and hyperresonance to percussion of the ipsilateral chest $[16,17]$. In addition, video-assisted thoracoscopy confirmed that local anesthetic liquid had been injected into the chest cavity. After the nerve block procedure, new symptoms, such as weakness, pain, tingling, paresthesia or numbness in the skin of the corresponding innervated area, indicated nerve injury. Thoracic nerve root pain is often described as burning or sharp, stemming from the back and traveling to other parts of the body connected to the damaged nerve. If the patient had the symptoms described above, further MRI scans or
CT scans was performed [18-20]. In this study, bleeding complications included the occurrence of vascular puncture, active bleeding, or hematoma formation caused by paravertebral block or retrolaminar block [21]. Bleeding complications were identified when blood was drawn back into the syringe during the nerve block operation or a chest wall hematoma was observed under thoracoscopy. The criteria for nerve block-related superficial soft tissue infection were swelling along the needle placement track, local tenderness along the needle placement track, fever $\left(>38.0^{\circ} \mathrm{C}\right)$, and leukocytosis $(>12 / \mathrm{nl}$ or C-reactive protein $(\mathrm{CRP})>20 \mathrm{mg} / \mathrm{l})$ [22]. The criteria for nerve block-related abscess or deep tissue infection were evidence of an abscess or fluid collection consistent with an infectious process by imaging or surgical exploration within 30 days after peripheral nerve block needle placement, fever $\left(>38.0^{\circ} \mathrm{C}\right)$, positive culture from surgical exploration or puncture, leukocytosis $(>12 / \mathrm{nl}$ or CRP $>20$ $\mathrm{mg} / \mathrm{l})$, local tenderness, focal back pain, and neurological deficit [22].

\section{Statistical analysis}

The primary outcome was the pain score at rest within the 48 -h period after surgery. In our preliminary study conducted in 10 adult patients (5 in each group), the mean NRS score at rest within the 48-h postoperative period was $2.0 \pm 1.6$ and $3.8 \pm 1.9$ in group $\mathrm{P}$ and group $\mathrm{R}$, respectively. We hypothesized that ultrasound-guided PVB would reduce the NRS score compared with RLB. 
PASS version 11.0.7 (PASS, NCSS, LLC, USA) for Windows was used to calculate the sample size. Student's ttest was selected, and the group allocation ratio was equal. The hypothesized means of the NRS scores were 2.0 and 3.8, and the standard deviations (SDs) were 1.6 and 1.9 , respectively. Then, we calculated that a sample of 27 patients would provide $90 \%$ power at a two-sided alpha level of 0.05 . Ultimately, we recruited 30 patients in each group for a total of 60 patients considering the possibility of dropout and loss to follow-up.

Continuous variables are presented as the mean \pm SD or median (25th to 75 th percentiles), and categorical data are presented as numbers and percentages. Normality was tested by Kolmogorov-Smirnov analysis. Student's t-test or Mann-Whitney $U$ test was used for analysis of the NRS score, intraoperative sufentanil consumption, total postoperative sufentanil consumption and duration of analgesia. For analysis of the MAP and HR data, repeated-measures ANOVA with Bonferroni correction was used. To analyze rescue flurbiprofen axetil, the incidence of adverse effects, Fisher's exact test was used. All data were processed by IBM SPSS Statistics 21.0 (IBM, Inc., New York, NY). A 2-sided $p$ value less than 0.05 was considered statistically significant.

\section{Results}

A total of 115 patients were recruited to participate in this study from March 2021 to July 2021. In all, 48 patients were ineligible because they did not meet the inclusion criteria or declined to participate, and 7 patients were excluded from the trial because of nonadherence to the study protocol ( 2 patients were lost to follow-up; 1 patient underwent secondary emergency surgery in $48 \mathrm{~h} ; 1$ patient temporally underwent a two-port operation instead of a uniportal operation during surgery; and 3 patients refused to use PCIA after surgery). Ultimately, 60 patients were randomized and completed the study protocol (group P: $n=30$; group $\mathrm{R}: \mathrm{n}=30$ ). The Consolidated Standards of Reporting Trials flow diagram depicts participant progression through the study phases (Fig. 1).

Ultimately, a total of 60 patients were included in the analysis in this study. There were no significant differences in the patient characteristics between the groups (Table 1). Additionally, there were no differences in the surgical method, duration of surgery or duration of anesthesia between the two groups (Table 1).

At $3,6,12,24,36$ and $48 \mathrm{~h}$ postoperatively, the NRS score at rest in group $\mathrm{R}$ was higher than that in group $\mathrm{P}$ $(p<0.05)$ (Fig. 5). At $3,6,12,24$ and $36 \mathrm{~h}$ postoperatively, the NRS score during coughing in group $\mathrm{R}$ was higher than that in group $\mathrm{P}(p<0.05)$ (Fig. 6). The intraoperative sufentanil consumption and total postoperative sufentanil consumption in group $\mathrm{P}$ were significantly lower than those in group $\mathrm{R}(p<0.001)$ (Table 1$)$.
Table 1 Demographic data and surgical and anesthetic characteristics

\begin{tabular}{|c|c|c|c|}
\hline & Group P & Group R & $\begin{array}{l}P \\
\text { value }\end{array}$ \\
\hline Age (years) & $53.7 \pm 14.0$ & $55.3 \pm 11.8$ & 0.630 \\
\hline $\mathrm{BMI}\left(\mathrm{kg} / \mathrm{m}^{2}\right)$ & $24.3 \pm 3.0$ & $23.2 \pm 3.5$ & 0.602 \\
\hline $\operatorname{Sex}(F / M)$ & $22 / 8$ & $25 / 5$ & 0.532 \\
\hline ASA classification (I/II) & $4 / 26$ & $6 / 24$ & 0.488 \\
\hline $\begin{array}{l}\text { Surgical method (uniportal } \\
\text { video-assisted lobectomy/uniportal } \\
\text { video-assisted wedge resection) }\end{array}$ & $20 / 10$ & $17 / 13$ & 0.434 \\
\hline Duration of surgery (min) & $\begin{array}{l}112.8 \pm \\
35.5\end{array}$ & $\begin{array}{l}116.23 \pm \\
49.9\end{array}$ & 0.762 \\
\hline Duration of anesthesia (min) & $\begin{array}{l}138.5 \pm \\
39.3\end{array}$ & $142.6 \pm 49.6$ & 0.724 \\
\hline $\begin{array}{l}\text { Intraoperative sufentanil } \\
\text { consumption }(\mu \mathrm{g})\end{array}$ & $\begin{array}{l}22.60 \pm \\
2.83\end{array}$ & $26.64 \pm 3.54$ & $<0.001$ \\
\hline $\begin{array}{l}\text { Total postoperative sufentanil } \\
\text { consumption }(\mu \mathrm{g})\end{array}$ & $\begin{array}{l}21.52 \pm \\
8.48\end{array}$ & $\begin{array}{l}38.91 \pm \\
13.27\end{array}$ & $<0.001$ \\
\hline $\begin{array}{l}\text { Rescue flurbiprofen axetil } \\
\text { (used/not used) }\end{array}$ & $2 / 28$ & $4 / 26$ & 0.671 \\
\hline $\begin{array}{l}\text { Rescue meperidine (used/not } \\
\text { used) }\end{array}$ & $0 / 30$ & $0 / 30$ & - \\
\hline
\end{tabular}

Data are expressed as the mean \pm SD for numbers. There were no significant differences between the groups. BMI body mass index, ASA American Society of Anesthesiologists, $F$ female, $M$ male, $P$ paravertebral block, $R$ retrolaminar block.

The MAP was significantly different at different time points in each group $(p<0.001)$. Similarly, the discrepancy in the HR at different time points was statistically significant $(p<0.01)$. However, no significant difference in the MAP or HR was observed between group $\mathrm{P}$ and group $\mathrm{R}$ ( $p=0.251$ and $p=0.079$, respectively) (Fig. 7).

Table 2 shows the number of patients experiencing adverse events. There was no significant difference in the incidence of bradycardia, hypotension, hypoxemia, respiratory depression, vomiting, pruritus, dizziness or neurotoxicity between group P and group R. However, the incidence of nausea in group $\mathrm{R}$ was higher than that in group $\mathrm{P}(p<0.05)$.

\section{Discussion}

In this study, we compared the analgesic effect of ultrasound-guided PVB and RLB after UVATS, and the NRS score within the 48-h period after surgery was the primary outcome. We found that compared with RLB, PVB could provide better analgesia both at rest and during coughing after surgery. Additionally, postoperative opioid consumption was deceased by PVB compared to $R L B$, and the incidence of nausea was lower after PVB than after RLB.

To date, only one study has reported the use of PVB and RLB for postoperative analgesia after thoracic surgery [23]. However, there were significant differences 


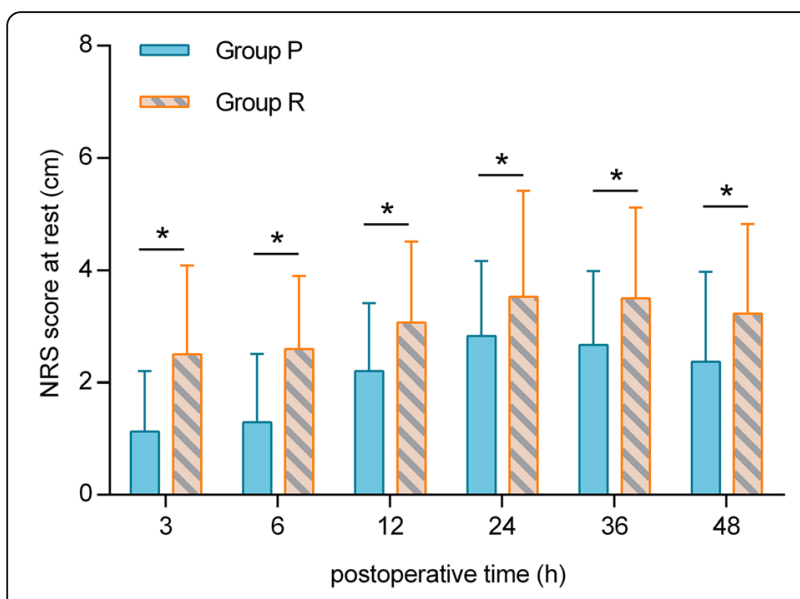

Fig. 5 Postoperative pain severity NRS score at rest (in $\mathrm{cm}$ ) at 3, 6, $12,24,36$ and $48 \mathrm{~h}$ postoperatively. $\mathrm{P}$, paravertebral block; $\mathrm{R}$, retrolaminar block; NRS, numerical rating scale. ${ }^{*} P<0.05$

between the previous study and this study in terms of research design. First, in a previous study conducted by Sugiyama et al., $0.5 \%$ ropivacaine was used for PVB, while $0.25 \%$ ropivacaine was used for RLB. Moreover, the volume of ropivacaine used for the two nerve block techniques was also quite different. Therefore, both the concentration and volume of local anesthetics used in the two nerve block techniques were completely different. A number of studies have confirmed that when the same local anesthetic is used for the same nerve block technique, different concentrations or volumes produce different analgesic effects [24-26]. Therefore, in the previous study conducted by Sugiyama et al., although the conclusion was that the analgesic effect of PVB was better than that of RLB after thoracic surgery, it was likely that the difference in the concentration and volume of

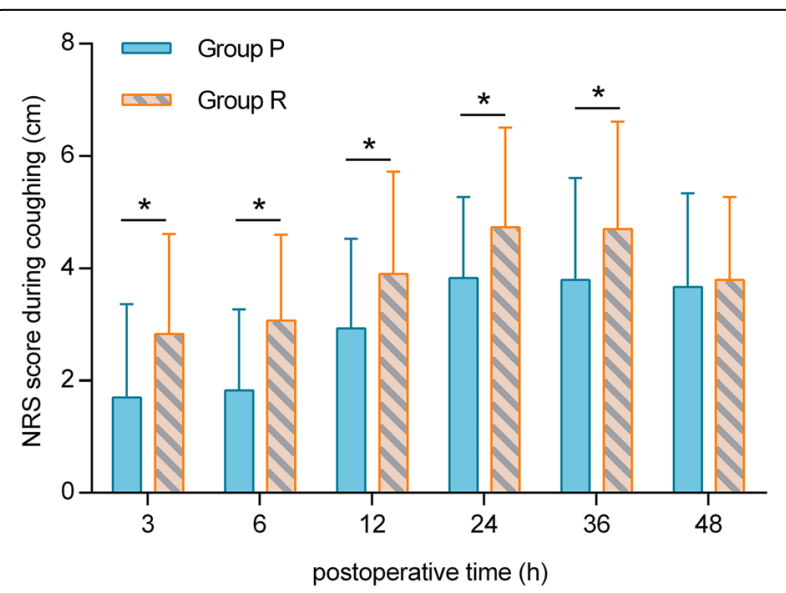

Fig. 6 Postoperative pain severity NRS score during coughing (in $\mathrm{cm})$ at 3, 6, 12, 24, 36 and $48 \mathrm{~h}$ postoperatively. $\mathrm{P}$, paravertebral block; $\mathrm{R}$, retrolaminar block; NRS, numerical rating scale. ${ }^{*} P<0.05$ local anesthetic drugs contributed to the different analgesic effects of the two nerve block techniques. In the previous study conducted by Sugiyama et al., it was difficult to distinguish whether the different analgesic effects were due to the different characteristics of the two nerve block techniques themselves or to the different concentrations or volumes of local anesthetic agents used. In contrast, in this study, the same concentration and volume of ropivacaine was used in either PVB or RLB to compare the analgesic effects of the two nerve block techniques. Therefore, in this study, the analgesic effects of these two nerve block techniques were comparable, and the conclusion was more convincing.

In addition, previous studies have indirectly compared the analgesic effects of PVB and RLB. After UVATS, Wang et al. confirmed that ultrasound-guided PVB could effectively alleviate postoperative pain and reduce postoperative opioid consumption [6]. Nagane et al. found that ultrasound-guided RLB effectively relieved postoperative pain after pulmonary lobectomy [15]. Furthermore, previous researchers have compared the analgesic effects of RLB and another similar thoracic nerve block, i.e., erector spinae plane block (ESPB). In addition, the analgesic effects of PVB and ESPB have been compared in thoracoscopic surgery. Sotome et al. found that RLB was equivalent to ESPB for analgesia after breast surgery using $20 \mathrm{ml}$ of $0.375 \%$ levobupivacaine [27]. Comparatively, Turhan et al. found that ultrasound-guided PVB could produce better analgesia and reduce opioid consumption than ESPB after VATS [28]. In addition, Chen et al. confirmed that compared with ultrasound-guided ESPB, ultrasound-guided PVB provided superior analgesia after thoracoscopic surgery [29]. Consistent with the aforementioned evidence, the results of this study suggest that ultrasound-guided PVB provided superior analgesia within $48 \mathrm{~h}$ after UVATS than ultrasound-guided RLB.

In this study, the target injection site of ultrasoundguided RLB was the posterior surface of the thoracic vertebral lamina [30]. Compared with PVB, the exact mechanism of analgesia of RLB was not completely clear. As revealed by Yang et al. in a cadaveric study, the probable mechanism of action for RLB was the spread of local anesthetics into the paravertebral space via the superior costotransverse ligament [14]. The anatomical basis was that although the superior costotransverse ligament was well developed at the T7 to T10 levels, it was rudimentary at the $\mathrm{T} 1$ to $\mathrm{T} 6$ levels [31]. In this study, RLB was performed at the T3 and T5 levels. Therefore, the ropivacaine solution was able to infiltrate easily into the paravertebral space. Ultimately, the anterior and posterior branches of the thoracic spinal nerves were blocked mainly by the indirect effect of RLB, and an analgesic effect was induced [32]. In contrast, PVB 

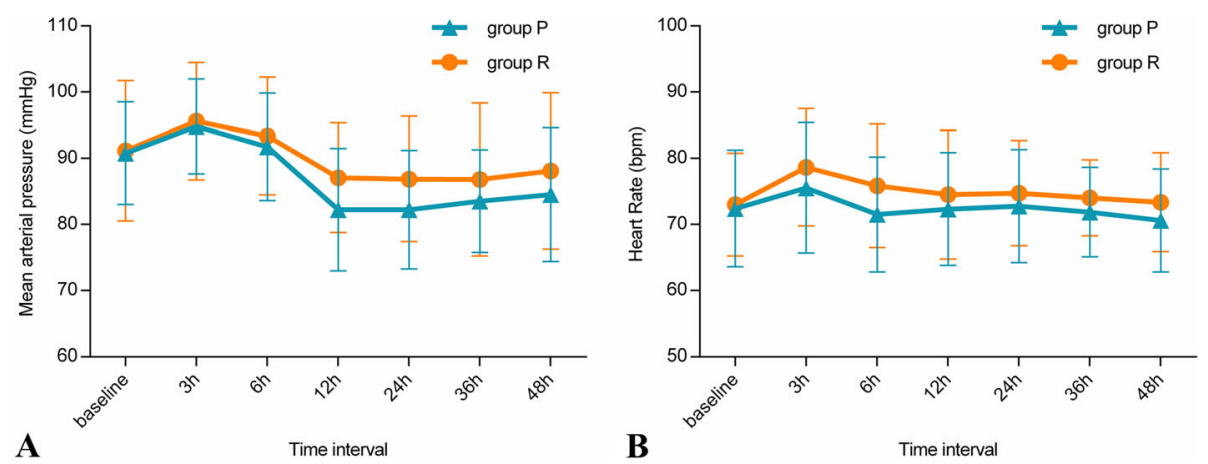

Fig. 7 A shows the mean arterial pressure (MAP) changes at different times in each group. In both groups, the MAP showed significant changes over time, with ${ }^{*} P<0.001$. B shows the heart rate (HR) changes at different times in each group. In both groups, the HR showed significant changes over time, with ${ }^{*} P<0.05$. $P$, paravertebral block; $R$, retrolaminar block

produces analgesia by directly depositing local anesthetics into the paravertebral space to block the ventral ramus and dorsal ramus of the spinal nerve root [33]. Compared with the indirect mechanism of RLB, the direct mechanism of PVB probably results in superior analgesia.

In this study, ultrasound-guided PVB exhibited an opioid-sparing effect compared to ultrasound-guided RLB. This can probably be attributed to the superior analgesic effect of PVB. In a previous clinical study, Turhan et al. noted that ultrasound-guided PVB reduced morphine consumption after thoracoscopic surgery [28]. Similarly, in thoracoscopic radical lung cancer surgery, ultrasound-guided PVB reduced postoperative oxycodone consumption [34]. In addition, Chen et al.

Table 2 Incidence of adverse events

\begin{tabular}{llll}
\hline Adverse events & Group P & Group R & $P$ value \\
\hline Adverse events related to block procedures & & \\
Pneumothorax or hydropneumothorax & $1(3)$ & $0(0)$ & 1.000 \\
Nerve injury & $0(0)$ & $0(0)$ & - \\
Bleeding complications & $0(0)$ & $0(0)$ & - \\
Infection & $0(0)$ & $0(0)$ & - \\
Other adverse events & & & \\
Bradycardia & $0(0)$ & $0(0)$ & - \\
Hypotension & $0(0)$ & $0(0)$ & - \\
Hypoxemia & $0(0)$ & $0(0)$ & - \\
Respiratory depression & $0(0)$ & $0(0)$ & - \\
Nausea & $1(3)$ & $8(27)$ & 0.026 \\
Vomiting & $1(3)$ & $4(13)$ & 0.353 \\
Pruritus & $0(0)$ & $0(0)$ & - \\
Dizziness & $2(7)$ & $4(13)$ & 0.671 \\
Neurotoxicity & $0(0)$ & $0(0)$ & - \\
\hline
\end{tabular}

The incidence of adverse effects data are expressed as numbers and percentages. $P$ paravertebral block, $R$ retrolaminar block. confirmed that ultrasound-guided PVB significantly reduced cumulative morphine consumption after thoracoscopic surgery [29]. The findings of the aforementioned previous studies are consistent with the results of this study. In addition, in this study, the incidence of nausea was lower with ultrasound-guided PVB than with RLB, which can probably be attributed to the reduced postoperative sufentanil consumption. As noted by Smith et al., opioids can induce nausea with or without vomiting, and this distressing symptom is related largely to the dose of opioid administered [35]. Similarly, Rivedal et al. found that PVB was associated with decreased opioid consumption and a decreased incidence of nausea and vomiting after breast surgery [36].

Compared with PVB, RLB is theoretically safer due to the anatomical avoidance of the pleura and vascular structures [37]. Additionally, because of the superficial anatomical location, RLB is technically easier to perform for clinical practitioners, especially for inexperienced novices [38]. In this study, only one patient suffered pneumothorax or hydropneumothorax during the ultrasound-guided PVB procedure. The reason for the low incidence of pneumothorax in this study might be that the anesthesiologists performing the PVB procedure were all attending doctors with a great deal of prior experience with the PVB technique. However, for anesthesiologists with less experience performing PVB, the riskto-benefit ratio might be better with RLB, which is more superficial than PVB.

There are several limitations to this study. First, this was a single-center, small-sample, exploratory clinical study, and further multicenter, large-sample clinical trials are needed to further confirm the conclusion of this study. Second, the type, concentration and volume of local anesthetic used in this study were specific. The results might not be suitable for generalization to include the use of different local anesthetics or volumes. Third, the surgical method observed in this study was UVATS. 
If the surgical procedure is changed to three-port thoracoscopic surgery or open thoracotomy, an inconsistent conclusion might be drawn. Therefore, further investigations in different surgical approaches for lung cancer are needed to verify the conclusions of this study.

\section{Conclusions}

In conclusion, the results of this study suggest that in patients with lung cancer undergoing UVATS, ultrasoundguided PVB with $0.5 \%$ ropivacaine provides better analgesia and results in less nausea than ultrasound-guided RLB. Compared with ultrasound-guided RLB, ultrasoundguided PVB seems to be a better technique for analgesia in UVATS.

\section{Abbreviations \\ UVATS: Uniportal video-assisted thoracoscopic surgery; PVB: Paravertebral block; RLB: Retrolaminar block; ASA: American Society of Anesthesiologists; BMI: Body mass index; HR: Heart rate; NRS: Numerical rating scale; PCIA: Patient-controlled intravenous analgesia; RR: Respiratory rate; $\mathrm{SpO}_{2}$ : Pulse oxygen saturation; PACU: Postanesthesia care unit; MAP: Mean arterial pressure}

\section{Acknowledgments}

Not applicable.

\section{Authors' contributions}

Qiang Wang contributed to the formal analysis, investigation, writing of the original draft and review and editing of the manuscript. Shijing Wei contributed to the data curation and investigation. Shuai Li contributed to the data curation and investigation. Jie Yu contributed to the data curation and investigation. Guohua Zhang contributed to the formal analysis, investigation and project administration. Cheng Ni contributed to the investigation, methodology and project administration. Li Sun contributed to the formal analysis, methodology and review and editing of the manuscript. Hui Zheng contributed to the acquisition of funding, supervision and review and editing of the manuscript. All authors have read and approved the final manuscript.

\section{Funding}

This study was funded by the Management Research Project Special Fund of the Cancer Hospital of the Chinese Academy of Medical Sciences (grant LC2018D01), Sanming Project of Medicine in Shenzhen (grant

SZSM201812069), Cancer Pain Treatment and Perioperative Medical Team of Professor Sun Li at Cancer Hospital, Chinese Academy of Medical Sciences. The sources of funding played no role in the study design, data collection or analysis or in the decision to publish or prepare the manuscript.

\section{Availability of data and materials}

The datasets generated or analyzed during the current study are available from the corresponding author on reasonable request.

\section{Declarations}

\section{Ethics approval and consent to participate}

This study was approved by the institutional ethics committee of the National Cancer Center/National Clinical Research Center for Cancer/Cancer Hospital, Chinese Academy of Medical Sciences and Peking Union Medical College (2020080419244502). Written informed consent was obtained from every patient.

\section{Consent for publication}

Consent for publication was obtained from the patients who participated in this study.

\section{Competing interests}

The authors declare that they have no competing interests.
Received: 22 July 2021 Accepted: 27 October 2021

Published online: 16 November 2021

\section{References}

1. Sung $H$, Ferlay J, Siegel $R L$, Laversanne $M$, Soerjomataram I, Jemal A, et al. Global cancer statistics 2020: GLOBOCAN estimates of incidence and mortality worldwide for 36 cancers in 185 countries. CA Cancer J Clin. 2021; 71(3):209-49. https://doi.org/10.3322/caac.21660

2. Sihoe ADL. Video-assisted thoracoscopic surgery as the gold standard for lung cancer surgery. Respirology. 2020;(Suppl 2):49-60. https://doi.org/1 $0.1111 /$ resp.13920

3. Elsabeeny WY, Ibrahim MA, Shehab NN, Mohamed A, Wadod MA. Serratus anterior plane block and erector spinae plane block versus thoracic epidural analgesia for perioperative thoracotomy pain control: a randomized controlled study. J Cardiothorac Vasc Anesth. 2021;35(10):2928-36. https:// doi.org/10.1053/j.jvca.2020.12.047

4. Patané AK. Minimal invasive surgery in locally advanced N2 non-small cell lung cancer. Transl Lung Cancer Res. 2021;10(1):519-28. https://doi.org/10.21 037/tlcr.2020.03.27.

5. Matsuura N, Igai H, Ohsawa F, Yazawa T, Kamiyoshihara M. Uniport vs. multiport video-assisted thoracoscopic surgery for anatomical lung resection-which is less invasive? J Thorac Dis. 2021;13(1):244-51. https://doi. org/10.21037/jtd-20-2759.

6. Wang L, Wang Y, Zhang X, Zhu X, Wang G. Serratus anterior plane block or thoracic paravertebral block for postoperative pain treatment after uniportal video-assisted thoracoscopic surgery: a retrospective propensity-matched study. J Pain Res. 2019;12:2231-8. https://doi.org/10.2147/JPR.S209012.

7. Zhao $H$, Xin $L$, Feng $Y$. The effect of preoperative erector spinae plane vs. paravertebral blocks on patient-controlled oxycodone consumption after video-assisted thoracic surgery: a prospective randomized, blinded, noninferiority study. J Clin Anesth. 2020;62:109737. https://doi.org/10.1016/j. jclinane.2020.109737.

8. Taketa Y, Irisawa Y, Fujitani T. Comparison of ultrasound-guided erector spinae plane block and thoracic paravertebral block for postoperative analgesia after video-assisted thoracic surgery: a randomized controlled non-inferiority clinical trial. Reg Anesth Pain Med. 2019:rapm-2019-100827. https://doi.org/10.1136/rapm-2019-100827.

9. Kelly ME, Nicholas DM, Killen J, Coyne J, Sweeney KJ, McDonnell J. Thoracic paravertebral blockade in breast surgery: is pneumothorax an appreciable concern? A review of over 1000 cases. Breast J. 2018;24(1):23-7. https://doi. org/10.1111/tbj.12831.

10. Schnabel A, Reichl SU, Kranke P, Pogatzki-Zahn EM, Zahn PK. Efficacy and safety of paravertebral blocks in breast surgery: a meta-analysis of randomized controlled trials. Br J Anaesth. 2010;105(6):842-52. https://doi. org/10.1093/bja/aeq265.

11. Naja Z, Lönnqvist PA. Somatic paravertebral nerve blockade. Incidence of failed block and complications. Anaesthesia. 2001;56(12):1184-8. https://doi. org/10.1046/j.1365-2044.2001.02084-2.x

12. Swisher MW, Wallace AM, Sztain JF, Said ET, Khatibi B, Abanobi M, et al. Erector spinae plane versus paravertebral nerve blocks for postoperative analgesia after breast surgery: a randomized clinical trial. Reg Anesth Pain Med. 2020;45(4):260-6. https://doi.org/10.1136/rapm-2019-101013.

13. Naja ZM, El-Rajab M, Al-Tannir MA, Ziade FM, Tayara K, Younes F, et al. Thoracic paravertebral block: influence of the number of injections. Reg Anesth Pain Med. 2006;31(3):196-201. https://doi.org/10.1016/j.rapm.2005.12.004.

14. Yang H-M, Choi YJ, Kwon H-J, O J, Cho TH, Kim SH. Comparison of injectate spread and nerve involvement between retrolaminar and erector spinae plane blocks in the thoracic region: a cadaveric study. Anaesthesia. 2018; 73(10):1244-50. https://doi.org/10.1111/anae.14408.

15. Nagane $D$, Ueshima $H$, Otake $H$. Upper lobectomy of the left lung using a left retrolaminar block. J Clin Anesth. 2018;49:74. https://doi.org/10.1016/j. jclinane.2018.06.014.

16. Ryan B. Pneumothorax: assessment and diagnostic testing. J Cardiovasc Nurs. 2005;20(4):251-3. https://doi.org/10.1097/00005082-200507000-00009.

17. Cottrell D. latrogenic pneumothorax. Nursing. 2010;40(3):72. https://doi.org/1 0.1097/01.NURSE.0000368828.45003.3f.

18. Netravathi M, Taly AB, Sinha S, Bindu PS, Goel G. Accidental spinal cord injury during spinal anesthesia: a report. Ann Indian Acad Neurol. 2010;13(4): 297-8. https://doi.org/10.4103/0972-2327.74200. 
19. Wong CA. Nerve injuries after neuraxial anaesthesia and their medicolegal implications. Best Pract Res Clin Obstet Gynaecol. 2010;24(3):367-81. https:// doi.org/10.1016/j.bpobgyn.2009.11.008.

20. Absalom AR, Martinelli G, Scott NB. Spinal cord injury caused by direct damage by local anaesthetic infiltration needle. Br J Anaesth. 2001;87(3): 512-5. https://doi.org/10.1093/bja/87.3.512.

21. Tsui BCH, Kirkham K, Kwofie MK, Tran Q, Wong P, Chin K, et al. Practice advisory on the bleeding risks for peripheral nerve and interfascial plane blockade: evidence review and expert consensus. Can J Anaesth. 2019; 66(11):1356-84. https://doi.org/10.1007/s12630-019-01466-w.

22. Schulz-Stübner S, Kelley J. Regional anesthesia surveillance system: first experiences with a quality assessment tool for regional anesthesia and analgesia. Acta Anaesthesiol Scand. 2007;51(3):305-15. https://doi.org/1 0.1111/j.1399-6576.2006.01239.x.

23. Sugiyama T, Kataoka Y, Shindo K, Hino M, Itoi K, Sato Y, et al. Retrolaminar block versus paravertebral block for pain relief after less-invasive lung surgery: a randomized, non-inferiority controlled trial. Cureus. 2021;13(2): e13597. https://doi.org/10.7759/cureus.13597.

24. Taha AM, Abd-Elmaksoud AM. Ropivacaine in ultrasound-guided femoral nerve block: what is the minimal effective anaesthetic concentration (EC90)? Anaesthesia. 2014;69(7):678-82. https://doi.org/10.1111/anae.12607.

25. Cappelleri G, Aldegheri G, Ruggieri F, Mamo D, Fanelli G, Casati A. Minimum effective anesthetic concentration (MEAC) for sciatic nerve block: subgluteus and popliteal approaches. Can J Anaesth. 2007;54(4):283-9. https://doi.org/1 0.1007/BF03022773.

26. Taha AM, Abd-Elmaksoud AM. Lidocaine use in ultrasound-guided femoral nerve block: what is the minimum effective anaesthetic concentration (MEAC90)? Br J Anaesth. 2013;110(6):1040-4. https://doi.org/10.1093/bja/a es595.

27. Sotome S, Sawada A, Wada A, Shima H, Kutomi G, Yamakage M. Erector spinae plane block versus retrolaminar block for postoperative analgesia after breast surgery: a randomized controlled trial. J Anesth. 2021;35(1):2734. https://doi.org/10.1007/s00540-020-02855-y.

28. Turhan Ö, Sivrikoz N, Sungur Z, Duman S, Özkan B, Sentürk M. Thoracic paravertebral block achieves better pain control than erector spinae plane block and intercostal nerve block in thoracoscopic surgery: a randomized study. J Cardiothorac Vasc Anesth. 2020;35(10):2920-7. https://doi.org/10.1 053/j.jvca.2020.11.034.

29. Chen N, Qiao Q, Chen RM, Xu QQ, Zhang Y, Tian Y. The effect of ultrasoundguided intercostal nerve block, single-injection erector spinae plane block and multiple-injection paravertebral block on postoperative analgesia in thoracoscopic surgery: a randomized, double-blinded, clinical trial. J Clin Anesth. 2020;59:106-11. https://doi.org/10.1016/j.jclinane.2019.07.002.

30. Zeballos JL, Voscopoulos C, Kapottos M, Janfaza D, Vlassakov K. Ultrasoundguided retrolaminar paravertebral block. Anaesthesia. 2013;68(6):649-51. https://doi.org/10.1111/anae.12296.

31. Ibrahim AF, Darwish HH. The costotransverse ligaments in human: a detailed anatomical study. Clin Anat. 2005;18(5):340-5. https://doi.org/10.1 002/ca.20102.

32. Onishi E, Toda N, Kameyama Y, Yamauchi M. Comparison of clinical efficacy and anatomical investigation between retrolaminar block and erector spinae plane block. Biomed Res Int. 2019;2019:2578396-8. https://doi.org/1 $0.1155 / 2019 / 2578396$

33. Seidel R, Wree A, Schulze M. Thoracic-paravertebral blocks: comparative anatomical study with different injection techniques and volumes. Reg Anesth Pain Med. 2020;45(2):102-6. https://doi.org/10.1136/rapm-2019-1 00896.

34. Kang K, Meng X, Li B, Yuan J, Tian E, Zhang J, et al. Effect of thoracic paravertebral nerve block on the early postoperative rehabilitation in patients undergoing thoracoscopic radical lung cancer surgery. World J Surg Oncol. 2020;18(1):298. https://doi.org/10.1186/s12957-020-02071-8.

35. Smith HS, Laufer A. Opioid induced nausea and vomiting. Eur J Pharmacol. 2014;722:67-78. https://doi.org/10.1016/j.ejphar.2013.09.074.

36. Rivedal DD, Nayar HS, Israel JS, Leverson G, Schulz AJ, Chambers T, et al. Paravertebral block associated with decreased opioid use and less nausea and vomiting after reduction mammaplasty. J Surg Res. 2018;228:307-13. https://doi.org/10.1016/j.jss.2018.03.018.

37. Bhalla PI, Solomon S, Zhang R, Witt CE, Dagal A, Joffe AM. Comparison of serratus anterior plane block with epidural and paravertebral block in critically ill trauma patients with multiple rib fractures. Trauma Surg Acute Care Open. 2021;6(1):e000621. https://doi.org/10.1136/tsaco-2020-000621.
38. Elkoundi A, Balkhi H, Bensghir M, Baite A. Levobupivacaine plasma level between erector spinae plane block and thoracic paravertebral block. Reg Anesth Pain Med. 2021;46(1):90-1. https://doi.org/10.1136/rapm-2020-101406.

\section{Publisher's Note}

Springer Nature remains neutral with regard to jurisdictional claims in published maps and institutional affiliations.
Ready to submit your research? Choose BMC and benefit from:

- fast, convenient online submission

- thorough peer review by experienced researchers in your field

- rapid publication on acceptance

- support for research data, including large and complex data types

- gold Open Access which fosters wider collaboration and increased citations

- maximum visibility for your research: over $100 \mathrm{M}$ website views per year

At BMC, research is always in progress.

Learn more biomedcentral.com/submissions 